\title{
Promoting Transition Success for Culturally and Linguistically Diverse Students with Disabilities: The Value of Mentoring
}

\author{
David Waldegrave Leake ${ }^{1}$, Sheryl Burgstahler ${ }^{2}$, Margo Vreeberg Izzo ${ }^{3}$ \\ ${ }^{1}$ Center on Disability Studies, University of Hawaii at Manoa, Honolulu, USA; \\ ${ }^{2}$ DO-IT (Disabilities, Opportunities, Internetworking, and Technology) Program, University of \\ Washington, Seattle, USA; \\ ${ }^{3}$ Nisonger Center, The Ohio State University, Columbus, USA. \\ Email: leake@hawaii.edu, sherylb@cac.washington.edu,izzo.1@osu.edu \\ Received February 24 ${ }^{\text {th }}$, 2011; revised April 5 ${ }^{\text {th }}$, 2011; accepted April 14 $4^{\text {th }}, 2011$.
}

\begin{abstract}
Youth with disabilities are less likely to enroll in and complete postsecondary education programs and transition to employment than their non-disabled peers, and this is especially so for those from culturally and linguistically diverse (CLD) backgrounds. To help provide insight into factors influencing the transition process, a multi-site study was conducted using survey interviews, focus groups, and case studies, with a focus on CLD youth with disabilities. The importance of mentoring emerged as a consistent theme. Most participants cited informal mentors as role models and key motivators for gaining the social, academic, and career supports needed for success. They identified the relationships of individuals who served as mentors and what they did that helped them gain fresh perspectives and take steps toward personal, academic, and career goals. The insights gained from the research participants support greater use of mentoring to help this population.
\end{abstract}

Keywords: Mentoring, Disabilities, Postsecondary Education, Cultural and Linguistic Diversity

\section{Introduction}

Modern society is so complex that youth often need the "expert help" of knowledgeable adults to develop healthy identities and successfully transition to adulthood (Hebert, 2001). The need for such adult support is particularly evident for youth with disabilities, who face greater difficulties in negotiating the transition process than their peers without disabilities. In addition to the various challenges associated with specific disabilities, nearly all youth with disabilities must also contend with social experiences of stigmatization and discrimination that may restrict their participation in normative school and community activities and thereby negatively impact their development of healthy identities (Gliedman \& Roth, 1980).

Numerous follow-up studies conducted over several decades confirm that having disabilities is associated with substantially poorer outcomes, on average, in employment, education, and community living (Baller, 1936; Blackorby \& Wagner, 1996; Newman, Wagner, Cameto, \& Knokey, 2009). The continuation of poor adult life outcomes for people with disabilities is especially distressing given the fact that over 30 years of legislation and research have focused on improving transition outcomes. Transition has emerged as a professional field of practice in special education guided by a set of national standards and quality indicators (National Alliance for Secondary Education and Transition, 2005). The Individuals with Disabilities

\footnotetext{
*The research reported in this article was funded by the US Department of Education's Office of Special Education Programs (OSEP) (Grant No. H324C010090). Additional support was provided by OSEP (Grant No. H327A060066), the Office of Postsecondary Education (Grant No. P333A050064), and the National Science Foundation (HRD-0833504, HRD-0929006, and HRD-0833561).
}

Education Improvement Act of 2004 (IDEA) defined transition services as a coordinated set of activities facilitating movement from secondary school to post-school activities including postsecondary education, vocational education, integrated employment, adult services, independent living, or community participation (IDEA, Section 602). According to this legislation, students with disabilities who qualify for special education must receive transition services that are coordinated through their Individualized Education Program (IEP), starting by the age of 16 years at the latest (IDEA, Section 614).

A widely shared goal in the field of transition has been to increase the proportion of youth with disabilities who go on to postsecondary education, whether it be a two-year, four-year, or vocational-technical institution. Not surprisingly, on average, individuals with disabilities who complete a postsecondary program experience significantly better employment and community living outcomes than those who do not (Flannery, Yovanoff, Benz, \& Kato, 2008; Flexer \& Baer, 2004; Gajar, 1998). However, individuals with disabilities attend postsecondary education at only about half the rate of their peers without disabilities (Wagner, Newman, Cameto, Levine, \& Garza, 2006).

One at-risk group of particularly high need consists of youth with disabilities of CLD heritage, who tend to experience significantly worse transition outcomes compared to peers who are White (Blackorby \& Wagner, 1996; Greene \& Nefsky, 1999; Henderson, 1999; US Department of Education, 2002). One contributing factor is that CLD students with disabilities are more likely to live in poverty and experience its negative effects compared to their White counterparts (Donovan \& Cross, 2002; Gil-Kashiwabara, Hogansen, Geenen, Powers, \& Powers, 2007). In addition, they may be subjected to the "double whammy" of being discriminated against and experiencing low 
expectations due to membership in two marginalized groups (having disabilities and being of CLD heritage) (Hollins, Downer, Farquarson, Oyepeju, \& Kopper, 2002).

One approach that has been shown to support at-risk youth through the transition to adulthood process is that of mentoring (Sipe, 1999). This article describes research evidence that this is indeed the case for CLD youth with disabilities who have the goal of obtaining a degree in higher education.

\section{Mentorship}

Mentoring is reported in the research and practice literature to be a powerful intervention for supporting people in various academic, employment, and community settings (Kilburg, 2007; Margolin, 2007; Mazurek-Melnyk, 2007; Rajuan, Beijaard, \& Verloop, 2007) and is often employed in projects funded by national organizations like the National Science Foundation and National Institutes of Health (Bhattacharjee, 2007). Although there has only been limited research on mentoring for youth with disabilities, it seems reasonable to assume that this population stands to benefit from this type of intervention (Sword \& Hill, 2003), as it provides the "personalized attention" that has been identified as an essential component of successful programs serving youth with various needs (Dynarski, 2001).

Mentoring is typically described as a relationship between an experienced, wiser adult and a younger person (sometimes referred to as the protégé) who may be struggling academically, behaviorally, or vocationally (Campbell-Whatley, 2001; Campbell-Whatley, Algozzine, \& Obiakor, 1997; Hamilton \& Hamilton, 1997). Such relationships are meant to foster personal bonds and provide a safe space for young people to express their feelings about academic, behavioral, career, and personal issues. It is hoped that the relationship skills that protégés gain as a result carry over into their other relationships. Socially supportive mentoring relationships can meet the individualized needs of protégés, including but not limited to counseling; role modeling; job shadowing; personal, academic, and career advice; and networking (Kram, 1985; Saito \& Blyth, 1992; Templin, Engeman, \& Doran, 1999). There is evidence that mentoring is most effective when mentor and protégé share important personal characteristics, such as gender and ethnic/racial heritage (Campbell \& Campbell, 2007).

Wanberg, Kammeyer-Mueller, and Marchese (2006) point out ways in which formal and informal mentoring scenarios differ. Mentors and protégés in informal mentoring situations are typically acquaintances who come to feel a personal bond, and their relationships may continue for a lifetime (Ragins, 2002). In formal mentoring, mentors are often paired with protégés on the basis of ethnic, career, or academic similarities, and their relationships are often specified to last a limited period of time and to focus on specific goals to address (e.g., academic, career, psychosocial) (Kram, 1985; Ragins \& Cotton, 1999). Although not as focused, informal mentoring is sometimes more effective than formal mentoring (Chao, Walz, \& Gardner, 1992; Ragins \& Cotton, 1999), perhaps because informal mentors are typically self-selected. Unfortunately, informal mentoring opportunities do not always present themselves to people who need a mentor.

Mentoring comes in many different forms. The prototypical mentoring model consists of one-on-one, face-to-face relationships, with mentor-protégé pairs meeting outside of work or school environments, participating in joint activities, and having relevant, supportive discussions. However, mentoring can also occur in group settings with qualified individuals leading discussions (Mitchell, 1999), such as a group of AfricanAmerican adolescent boys in foster care who meet weekly with a mental health professional to discuss problems and other issues, particularly those relevant to their specific cultural group (Utsey, Howard, \& Williams, 2003). In such group mentoring environments, protégés learn not only from their mentors but also from one another, and have opportunities to mentor each other by offering advice, encouragement, and information. Some research suggests that compared to one-on-one models, group mentoring has the advantage of promoting positive peer interactions (Burgstahler \& Cronheim, 2001; Herrera, Vang, \& Gale, 2002; Sipe \& Roder, 1999)

Online mentorship programs offer an alternative to face-toface meetings and have grown in popularity along with that of Internet-enabled relationships and social networks. Potential benefits include lower cost, increased access to people in diverse geographical locations, and fewer limitations with respect to meeting location and schedule, while a weakness of a strictly virtual mentoring model is that text-based communications can be inaccurately interpreted due to the lack of social cues (Burgstahler \& Cronheim, 2001; Lavin-Colky \& Young, 2006).

Virtual mentoring can be particularly helpful for youth with disabilities who may have difficulty getting to physical meeting sites on their own. It can also help to bring together those with low incidence disabilities who tend to be widely dispersed. For those with various sensory or communication impairments, computer technologies now exist to enable communication (e.g., text readers can voice the contents of emails for those with visual impairments). A supportive mentoring community can thus be created for youth with disabilities who, without a virtual connection, may not otherwise be able to easily participate. This benefit of e-mentoring for students with disabilities is evident in the group mentoring model employed by the DO-IT (Disabilities, Opportunities, Internetworking, and Technology) Center at the University of Washington in Seattle (Burgstahler, 2007; Burgstahler \& Cronheim, 2001). Mentoring groups are comprised of peers, near-peers (individuals a few years older than the youngest participants), and adult mentors. Young college students are particularly powerful role models for high school students who have college enrollment as a goal. In DO-IT, many participants have opportunities to meet each other in person, but the online option allows mentors and protégés to communicate across great distances.

Regardless of its characteristics (e.g., formal or informal, online or on-site, individual or group), mentoring shows promise for improving the social, academic, and career success of youth with disabilities, including those of CLD heritage. Little is known, however, about different cultural perspectives on how mentoring occurs and on its value to these individuals. Such information would be useful to families, educators, and programs aiming to increase the academic and career success of CLD students with disabilities.

\section{Research Questions}

The authors and several other university-based investigators conducted a multi-method study at five sites across the United States to identify and examine key factors influencing the transi- 
tion to postsecondary education of youth with disabilities, with a focus on those of CLD heritage. This article summarizes the results of analyzing the subset of data relevant to the issue of mentoring, with a focus on answering two research questions:

- In what contexts and with whom do mentoring relationships occur for youth with disabilities, especially those of CLD heritage?

- What is the perceived value of mentoring to youth with disabilities, especially those of CLD heritage?

\section{Methods}

\section{Research Design}

The research sites were located in the states of Arizona, Hawaii, North Carolina, Ohio, and Washington. Each site used the same research instruments and methods. These methods included 1) conducting a telephone interview survey of youth with disabilities who had exited high school, 2) conducting multiple focus groups of those who had achieved success in postsecondary education, and 3) developing in-depth case studies. The rationale for this design was that the telephone interview survey would begin to identify factors of likely importance for the target population, and these factors would then be explored in greater depth through qualitative focus group and case study approaches.

In order to obtain consumer guidance, each of the five research sites assembled a participatory action research (PAR) team consisting primarily of CLD individuals with disabilities who had demonstrated success in postsecondary education. The PAR teams gave feedback on the design of research activities and reviewed research instrument drafts, which were revised in response to their input.

\section{Participants}

Interview Survey. Primary participation criteria were that participants had been out of high school between one and five years and had had an IEP. The goal was for roughly half of the participants to have attended a postsecondary institution and the other half to have not attended, so that key factors differentiating these two groups might be revealed. Identifying and recruiting young adults with disabilities turned out to be difficult, despite offering compensation of $\$ 25$. The researchers used their established relationships with local disability service agencies and support organizations to locate and recruit individuals with no postsecondary education experience. However, they found it was easier to reach individuals attending college thanks to help from on-campus offices for disability support services. As a result, of the 198 survey participants, 152 (76.8\%) had college experience and $46(23.2 \%)$ did not. There were 92 females (46.5\%) and 106 males (53.5\%). Their racial/ethnic self-ascriptions were 28 American Indian (14.1\%), 17 Asian (8.6\%), 55 Black (27.8\%), 14 Hispanic (7.1\%), 12 Pacific Islander (6.1\%), 50 White (25.3\%), and 22 other or multiethnic (11.1\%).

Focus Groups. The next research phase involved convening a total of 12 focus groups consisting of a total of 60 young adults with college experience, most identified and recruited from among those in the telephone survey, although some sites had to conduct additional recruiting. Participants included 35
(58.3\%) females and 25 (41.7\%) males. Regarding primary disability, participants included 23 (38.3\%) with learning disabilities or dyslexia, 10 (16.7\%) with attention deficit disorder (with or without hyperactivity), 7 (11.7\%) with visual impairments, 5 (8.3\%) with traumatic brain injury, 3 (5.0\%) with mobility impairments, 2 (3.3\%) with hearing impairments, 2 (3.3\%) with developmental disabilities, and 2 (3.3\%) with serious emotional disturbances. The remaining 6 (10.0\%) were either the only ones with their particular primary disability or their disabilities were unknown.

Case Studies. In the third research phase, each of the sites conducted in-depth case studies of 11 participants whose stories seemed to illustrate how young CLD adults with disabilities can be effectively supported to succeed in postsecondary education. In contrast to the first two phases, White participants were not included, based on the assumption that while useful CLD versus non-CLD cultural contrasts would emerge from comparesons of both the interview survey and focus group results, there would not be enough case study participants for meaningful comparisons. The racial/ethnic self-ascriptions and locations of the case study participants are shown in Table 1.

\section{Instruments}

Each of the three research methods was conducted using different instrumentation. Instruments were designed to address topics identified through a literature review (summarized in Leake et al., 2006) as highly relevant to successful transitions to adulthood, including the participants' family backgrounds, their disabilities, the services and supports they received in high school, their use of assistive technology, their friendships, and their educational and vocational experiences since leaving high school.

Interview Survey. The survey questionnaire consisted of 62 items, most of which were adapted from instruments used in previous transition follow-along research (Izzo, Sharpe, \& Murray, 2002; James \& Leake, 1994) and the California Workability I Follow-up Survey of special education school leavers.

Table 1.

Research sites and numbers of research participants.

\begin{tabular}{|c|c|c|c|}
\hline $\begin{array}{l}\text { University } \\
\text { Site }\end{array}$ & $\begin{array}{l}\text { \# Phone Survey } \\
\text { Participants }\end{array}$ & $\begin{array}{l}\text { \# Focus Group } \\
\text { Participants }\end{array}$ & $\begin{array}{l}\text { \# Case Study } \\
\text { Participants }\end{array}$ \\
\hline $\begin{array}{l}\text { North } \\
\text { Carolina }\end{array}$ & $\begin{array}{l}17 \text { Round } 1 \\
5 \text { Round } 2\end{array}$ & 12 Black (2 groups) & 2 Black \\
\hline Arizona & $\begin{array}{l}37 \text { Round } 1 \\
17 \text { Round } 2\end{array}$ & $\begin{array}{l}6 \text { American Indian } \\
6 \text { Hispanic }\end{array}$ & $\begin{array}{l}2 \text { American } \\
\text { Indian }\end{array}$ \\
\hline Ohio & $\begin{array}{l}62 \text { Round } 1 \\
30 \text { Round } 2\end{array}$ & $\begin{array}{c}8 \text { Black (+1 Asian) } \\
4 \text { White }\end{array}$ & 2 Black \\
\hline Hawaii & $\begin{array}{l}70 \text { Round } 1^{a} \\
25 \text { Round } 2\end{array}$ & $\begin{array}{c}4 \text { Asian } \\
3 \text { Hispanic } \\
3 \text { Native Hawaiian } \\
5 \text { White }\end{array}$ & $\begin{array}{c}1 \text { Asian } \\
2 \text { Pacific } \\
\text { Islander } \\
1 \text { Hispanic }^{\mathbf{b}}\end{array}$ \\
\hline Washington & $\begin{array}{l}12 \text { Round } 1 \\
1 \text { Round } 2\end{array}$ & $\begin{array}{l}4 \text { Asian } \\
4 \text { Hispanic }\end{array}$ & 1 Hispanic \\
\hline TOTAL & $\begin{array}{c}198 \text { Round } 1 \\
78 \text { Round } 2\end{array}$ & 60 (12 groups) & 11 \\
\hline
\end{tabular}

a. Includes 33 participants in Arizona, California, Michigan, and Texas; b. Resident of Colorado. 
The instrument was revised three times based on field testing and the recommendations of the five PAR teams. One of the survey items addressed the issue of mentoring: "Did you have a mentor during high school? Someone who supported you and gave you advice?” Participants who responded positively were then asked to describe who their mentors were and how their mentors had supported them.

Focus Groups. Focus group discussions were guided by a standard set of 22 probe questions, with three subsets of questions addressing family and social factors, high school experiences, and postsecondary education experiences (see Table 2). One of the questions in the family and social factors subset concerned mentors: "How much of your success in postsecondary education do you think is due to the influence of adult mentors or role models (relatives, teachers, etc.) during your teen years and since? Who were they and how did they help you?" An additional mentor question was included in the questions on postsecondary education experiences: "Are there professors/instructors, other students, or anyone else you look up to as role models or mentors? Who are they and how do they help you?"

Case Studies. The case study guidelines listed 19 issues to explore with each participant, including an issue directly relevant to mentoring: "Who were key people who supported you to attend postsecondary education? In what specific ways did these key people provide supports?”

\section{Procedures and Analysis}

Interview Survey. Researchers scheduled interviews with prospective participants who submitted signed informed consent forms. The interviews typically lasted 40 minutes and were generally conducted via telephone, although one site conducted face-to-face interviews with American Indian participants as recommended by its PAR team. Interview responses were analyzed using SPSS software, primarily using descriptive statistics and the general linear model (GLM).

Focus Groups. Focus groups were formed of individuals of similar ethnic/racial heritage, based on the assumptions that: 1 ) consistent cultural themes might be more likely to emerge in discussions among individuals from similar cultural backgrounds, and 2) participants might feel more relaxed and selfrevelatory in the presence of others who shared their heritage. The three domains covered by the standard probe questions were addressed either in separate sessions lasting around two hours, or in a single all-day session. The focus group sessions were recorded and transcribed, and the transcripts were analyzed using Atlas.ti, a qualitative data analysis software program. Atlas.ti allows sections of text to be coded as to the theme or topic of discussion, and all text segments with a particular code or codes can then be extracted for comparison. A total of 128 transcript segments were coded as concerning mentors or role models.

Case Studies. The case studies were designed to gather information from multiple sources about how the participants achieved postsecondary education success. Interviews were conducted not only with the participants, but also with other people they identified as having played key roles. For most participants, these people included parents, other relatives, and teachers. Analysis involved examining the interview transcripts to distill answers to the questions posed in the case study
Table 2.

Focus group probe questions (questions about mentors in bold italics).

First Focus Group Session: Family Supports

- Who in your family has normally made the decisions about your education?

- What did your family think you should do after high school? Did they encourage and support you to go on to postsecondary education?

- Is family involvement in homework and school activities during high school critical to a successful postsecondary education?

- Is family involvement during postsecondary education (choosing classes, helping with transportation, etc.) important for student success?

- Are youth whose parents had a postsecondary education more likely to have postsecondary education as a goal than those whose parents did not?

- How much of your success in postsecondary education do you think is due to the influence of adult mentors or role models (relatives, teachers, etc.) during your teen years and since? Who were they and how did they help you?

- Do you consider your family to be in the lower, middle, or upper income bracket?

\section{Second Focus Group Session: High School Experiences}

- Did you like going to high school? Why or why not?

- How would you rate the quality of your high school (teachers, facilities, etc.)?

- Reflecting on your experiences in high school: What made you feel most valued? What made you feel least valued? Please describe specific situations to illustrate.

- What were your teachers' expectations of you during high school? Did they encourage you to attend a postsecondary institution?

- Were you involved in developing your own Individualized Education Plan (IEP) and Individualized Transition Plan (ITP)? Were these plans designed to help you go on to postsecondary education?

- What were the main interests of you and your friends in high school? What did you usually do together? What did they do after leaving high school?

- What were the main ethnic/racial groups in your high school? Which groups did your friends belong to?

Third Focus Group Session: Postsecondary Experiences

- Did you consider the services and supports available for students with disabilities in choosing a postsecondary institution?

- Do you feel accepted as an equal on campus, like you "belong"? Do you ever feel like you are viewed or treated negatively on campus? If so, do you think it is related to your disability, or your CLD status, or both, or neither? Please explain.

- Are there professors/instructors, other students, or anyone else you look up to as role models or mentors? Who are they and how do they help you?

- Have you identified yourself as a student with disabilities? Why or why not?

- Are there services or supports that you think you need but aren't getting? Why not? What have you done to solve this problem?

- What are your education and career goals? How will you judge if you are successful or not in life in general?

- Is the cost of postsecondary education a problem for you? If it is a problem, how are you dealing with it?

- Did your ability to pay for postsecondary education affect your choice of institution? How?

guidelines.

\section{Results}

\section{Telephone Interview Survey}

Table 3 summarizes responses to the survey question, "Did 
Table 3.

Interview survey answers to: "Did you have a mentor during high school? Someone who supported you and gave you advice?”

\begin{tabular}{ccccc}
\hline Subgroup & Yes & No & Don’t Know & TOTAL \\
\hline American Indian & $18(66.7 \%)$ & $9(33.3 \%)$ & $0(0 \%)$ & $27(100 \%)$ \\
Asian & $11(84.6 \%)$ & $1(9.1 \%)$ & $1(9.1 \%)$ & $13(100 \%)$ \\
Black & $29(52.7 \%)$ & $17(30.9 \%)$ & $9(16.4 \%)$ & $55(100 \%)$ \\
Hispanic & $9(69.2 \%)$ & $3(23.1 \%)$ & $1(7.7 \%)$ & $13(100 \%)$ \\
Pacific Islander & $5(50.0 \%)$ & $5(50.0 \%)$ & $0(0 \%)$ & $10(100 \%)$ \\
White & $26(52.0 \%)$ & $18(36.0 \%)$ & $6(12.0 \%)$ & $50(100 \%)$ \\
Multiethnic/Other & $21(70.0 \%)$ & $8(26.7 \%)$ & $1(3.3 \%)$ & $30(100 \%)$ \\
TOTAL & $119(60.1 \%)$ & $61(30.8 \%)$ & $18(9.1 \%)$ & $198(100 \%)$ \\
In College & $83(56.8 \%)$ & $46(31.5 \%)$ & $17(11.6 \%)$ & $146(100 \%)$ \\
Not in College & $36(69.2 \%)$ & $15(28.8 \%)$ & $1(2.0 \%)$ & $52(100 \%)$ \\
\hline
\end{tabular}

you have a mentor during high school? Someone who supported you and gave you advice?” There was variability across the ethnic/racial subgroups (from a 50.0\% “yes” response rate for Pacific Islanders to $84.6 \%$ for Asians) which appears attributable to the relatively low numbers of respondents in each subgroup. Across the subgroups, the "yes" response rate was approximately $60 \%$ and the "no" response rate was approximately 31\% (with about 9\% responding “don’t know”).

An interesting finding was that $69.2 \%$ of the 52 interviewees not in college reported having a mentor during high school compared to only $56.8 \%$ of the 146 who attended college. However, this difference is not statistically significant (when the "don't know" responses are excluded, a $2 * 2$ comparison using Fisher's exact test (two-tailed) returns a $P$ value of 0.4868). The relatively low rate of mentorship during high school reported by those who attended college raises questions about how they negotiated barriers - did they manage on their own or were they significantly supported by parents or other family members? The intent of the question was to identify mentors from outside the immediate family, and this seems to be how the question was generally understood since only $14.9 \%$ of interviewees who reported kind of mentor responded "parent".

\section{Focus Groups}

The focus group transcripts indicated that 55 out of 60 participants were recorded discussing their experiences of being mentored, with only one of the 55 stating they had had no mentors in either high school or college. In analyzing the relevant focus group transcript segments, three themes emerged regarding mentorship, as described below.

Who Do Youth View as Mentors? The focus group transcripts were examined to identify the people described by the participants as their mentors. Many participants described having multiple mentors. Of the 54 focus group participants who recalled being mentored, 30 (55.6\%) specified parents or other close relatives, 20 (37.0\%) teachers, 8 (14.8\%) school counselors, $6(11.1 \%)$ friends or peers, 4 (7.4\%) other high school personnel, 4 (7.4\%) college disability support services personnel, and $3(5.6 \%)$ a romantic partner. Other individuals mentioned included therapist, work supervisor, and neighbor.

Research indicates that mentoring relationships may be stronger and more effective when mentors and protégés share the same ethnic/racial identity and/or disability status (Campbell \& Campbell, 2007). Some support for this idea was found in the focus group transcripts, although it was not specifically addressed by the probe questions. For example, an American Indian female with a visual impairment said:

...for me it's a [professor] but at the same time he's Native American, he's [name of tribe], so he really relates to me a lot, he's pretty cool. He's already asking me, "How many more years 'til you graduate?" and "We're gonna find a good university for you," and he's always trying to get me involved in a lot of programs and um he wants me to get an internship.

An example of the possible importance of sharing disability status was provided by an Asian female who is deaf, who recounted that in high school:

The deaf and hard of hearing coordinator was deaf, so she was responsible for my IEP, I guess, whatever. So, because she was deaf I looked up to her and she's the one who encouraged me to go to college and sort of pushed me to do well in classes and also to go to college as well.

What Do Mentors Do? Analysis of the focus group transcripts reveals that the most-often described ways that mentors help are (in descending order of frequency): encouraging and motivating; serving as examples of success (e.g., succeeding in college despite disability-related barriers); providing emotional support when things are not going well; discussing or guiding plans for the future; providing educational support (e.g., helping with homework); helping to negotiate service systems; and treating people with disabilities just like other people.

Do You Serve As a Mentor or Role Model to Others? A number of focus group participants expressed commitment to serving as mentors or role models for others who may face barriers related to disability or CLD status. Some explained that this commitment contributed to their motivation to succeed in college. For example, a Hispanic male with paraplegia explained that, "I decided to motivate myself [to go to college] because I want to be a role model for all those people" who might let their disabilities keep them out. And a Black female with learning disabilities said:

You read the history of African Americans and people who died to have the right to vote, or the right to walk into a grocery store or restaurant. That has encouraged me to keep moving in times where you feel like you can't do this paper. But you have people looking at you. So I want little girls at my elementary school to say that they want to be like [me] and go to college.

A Hispanic female who has multiple orthopedic disabilities explained:

My base influence for why I am continuing my education is my little brother. Because boys are more likely not to go to college and he could do way more for himself. So that's why I try to continue my education and show him that even though I have some barriers, that I can do it and so it's more easier for him to do it.

\section{Case Studies}

All 11 of the case study participants reported that mentors 
played significant supportive roles in their college journeys. Several of the participants specifically stated that they would not have attended college without such support. In view of the depth and breadth of the case study data, it is worth summarizeing how each participant benefited from mentoring.

- An American Indian female with a visual impairment identified a professor as a key mentor who recognized her academic potential and took her under his wing, encouraging and supporting her to do things she would not otherwise have considered, including doing a summer internship in another state and preparing to attend graduate school.

- An American Indian male with a learning disability grew up on a reservation and probably would not have considered going to college but for the fact he began receiving athletic scholarship offers while just a sophomore in high school. As a result of his outgoing personality and strong self-advocacy skills, he developed mentoring relationships with numerous people, including his high school and college athletic coaches. Guidance from an older brother and another athlete from the same high school who went to college ahead of him was also important.

- A Black male with a traumatic brain injury was a star athlete and acknowledged leader in high school but, after his accident during senior year, he had to adjust to having to depend on other people to help deal with his new cognitive limitations. Key mentors have included his mother and an older friend who completed college.

- A Black female with a hearing impairment attributes her perseverance through academic and financial difficulties to the support of her parents, especially her mother. She has also benefited from the advice and support of her sister, two work supervisors, and members of her sorority.

- A Black female who is legally blind was supported throughout her K-12 school years by her parents and numerous other family members. An older male cousin served as a role model and mentor with regard to attending college, and her grandmother mentors her at the hospital where they both work.

- A Black female who is legally blind identified an older woman who is also visually impaired as a key influence:

It really made a tremendous difference being able to talk to [her] about practically anything and knowing she had first-hand knowledge and superior advice. I don't mean to say that mentors are infallible people because they're not. They just help students to see that any hard time they find themselves in won't last forever.

- A Hispanic female with a severe orthopedic condition was supported by her parents and K-12 teachers, who recognized and fostered her academic potential and drive to succeed. Her most significant mentor in college was her older sister, who attended the same institution.

- A Hispanic female with learning disabilities began college after her children had grown up with the aim of building on her experience as a paraeducator to obtain a teaching certificate. One inspiration was her younger brother, who has a master's degree, and she was supported by several professsionals who helped her to understand and effectively manage her learning disabilities.

- An Asian (Japanese) male with cerebral palsy has always been encouraged by his family to go as far as possible aca- demically, in line with their high cultural valuation of education. A number of fellow students helped him through the seven years it took him to earn his bachelor's degree, after which he entered graduate school in pursuit of a master's degree. One of his professors in particular was instrumental, helping him negotiate the vocational rehabilitation bureaucracy to obtain a voice synthesizer and also involving him in initiatives to support other people with disabilities through assistive and multimedia technologies.

- Two Pacific Islander females who are deaf share much the same story. They were befriended by special education consultants visiting their high school on a remote Pacific island. The consultants recognized their academic potential and arranged for them to attend a community college with a strong deaf program in the United States where they learned American Sign Language. Numerous mentors supported their college and independent living progress, including an older couple who are also deaf with whom they initially stayed, personnel within the community college deaf program, an employer who knows sign language, and other young adults in the local deaf community with whom they frequently socialize.

In turn, all of the case study participants expressed the desire to serve as mentors or role models for others with disabilities, and many expressed career goals in this vein. For example, the Black male with traumatic brain injury said he wants to be a motivational speaker to inspire others facing similar barriers, and both Pacific Island females who are deaf said they want to return to their home island to introduce American Sign Language.

\section{Discussion}

Although about $40 \%$ of young adults with disabilities who took part in the standardized interview said they either did not have a mentor during high school or could not remember, nearly all focus group participants and all case study participants did describe having mentors. A reasonable explanation of this difference in reported rates of mentorship may be that the conversational and more in-depth nature of the focus groups and case studies may have elicited more positive answers by clarifying what was meant by mentoring and encouraging reflection.

There has been very little research to date on mentoring to promote postsecondary education success for students with disabilities, and virtually no research specifically focused on those of CLD heritage. The results of our focus group and case study phases provide preliminary evidence of the potential importance of mentoring for this population. By looking up to others who have succeeded-teachers, family members, parents, formal mentors, near-peers - these youth are better able to envision their own success and work toward their goals. Those most often cited as mentors by the research participants are individuals with whom they have most often been in routine contact - teachers, family members, and friends. These individuals should keep in mind the role for which they have been informally selected.

Notably, very few of the focus group members, and none of the case study participants, described having been involved in formal mentoring relationships. This result raises the possibility that poor transition outcomes for many youth with disabilities 
may be partly related to the lack of informal mentors and role models among those with whom they routinely associate-a situation that is more likely to occur in impoverished communities, where CLD groups tend to comprise a higher proportion of the populace. The implementation of a formal mentoring program can help fill this gap. Administrators, faculty members, and teachers who direct, or desire to direct, intentional mentoring programs should keep in mind the social, academic, and career supports that CLD youth with disabilities report as instrumental in their successful transition to college and careers. As mentors build their relationships with their protégés they can provide the motivation to persist through challenging circumstances; the cultural connections to feel they are valued members of their groups; and other natural supports such as facilitating entrée to clubs and associations, modeling social skills, or promoting friendships with others. Mentors can encourage protégés to use academic supports such as high school to college bridge programs, college visits, classroom accommodations, and study supports. Career supports that mentors can provide include access to career education programs or work-based learning such as job shadowing, job tryouts, and internships, as well as access to social networks knowledgeable of job opportunities.

The results of this study indicate that those in both informal and formal mentoring roles can be effective in encouraging their protégés to take critical steps toward successful transitions to higher academic levels and careers. Administrators, educators, and counselors at both the secondary and postsecondary levels should encourage their colleagues to engage in and facilitate both formal and informal mentoring of CLD youth with disabilities. Table 4 outlines many of the social, academic, and career supports that can come from both informal and formal mentors. Having an experienced adult or near-peer role model who has the experience to recommend the use of classroom accommodations such as assistive technology or extended time on tests may increase achievement and success in academic settings. Formal mentoring programs can help mentors learn to provide culturally sensitive supports and self-determination activities such as explaining how assistive technology and other accommodations improved their own performance. Educators can build these informal mentoring opportunities through cross-age tutoring programs, community service opportunities, and specific classroom assignments that require students to "pay it forward" by mentoring younger students.

With regard to promoting the use of informal mentoring, it is interesting to note that mentoring is typically one of the beneficial outcomes of natural supports (Westerlund, Granucci, Gamache, \& Clark, 2006). Natural supports emerge from the social relationships that people develop in their various life domains, but disabilities often create barriers to developing and maintaining relationships (Nisbet, 1992). Practices that support people with disabilities to expand their social networks-such as person-centered planning that creates "circles of friends" or "circles of support” (Mount, 1997)—can therefore increase and enhance the mentoring they receive.

Cultural sensitivity should be incorporated into both mentor and protégé training activities so mentors are aware of cultural norms that, if ignored, might invalidate the mentoring relationship. For example, CLD youth may be more oriented to the traditional collectivistic values of their ethnic/racial group than
Table 4.

Examples of social, academic, and career supports provided by family members, school personnel, work colleagues, peers, and other mentors.

\begin{tabular}{|c|}
\hline $\begin{array}{l}\text { SOCIAL SUPPORTS } \\
\text { Motivation } \\
\text { - Endorse self-determined choices } \\
\text { - Inspire to persevere } \\
\text { - Model persistence } \\
\text { - Positive role model } \\
\text { Cultural Connections } \\
\text { - Introduce to others of similar heritage } \\
\text { - Inform of cultural events } \\
\text { - Help understand cultural heritage/values } \\
\text { Natural Supports } \\
\text { - Facilitate entrée to clubs, etc. } \\
\text { - Model social skills } \\
\text { - Promote friendships } \\
\text { - Counsel on relationship problems }\end{array}$ \\
\hline $\begin{array}{l}\text { ACADEMIC SUPPORTS } \\
\text { Bridge Programs } \\
\text { - College classes while in high school } \\
\text { - College orientation } \\
\text { - Summer academic preparation } \\
\text { Culturally Sensitive Self-determination } \\
\text { - Self-determined college visits } \\
\text { - Self-determined course of study } \\
\text { Study Assistance } \\
\text { - Peer tutoring } \\
\text { - Study groups } \\
\text { - Discussions with faculty } \\
\text { Accommodations } \\
\text { - Assistive technology } \\
\text { - Extended time on tests } \\
\text { - Note takers }\end{array}$ \\
\hline $\begin{array}{l}\text { CAREER SUPPORTS } \\
\text { Career Exploration } \\
\text { - Curriculum-based career education } \\
\text { - Job shadowing } \\
\text { - Job tryouts } \\
\text { - Career research } \\
\text { Culturally Sensitive Self-determination } \\
\text { - Self-determined career goal } \\
\text { - Self-advocacy for accommodations } \\
\text { Work-based Learning } \\
\text { - Work experiences } \\
\text { - Research experiences } \\
\text { - Internships } \\
\text { Job Seeking Network } \\
\text { - Provide references } \\
\text { - Inform of job openings } \\
\text { - Introduce to employers }\end{array}$ \\
\hline
\end{tabular}

the individualistic values typically held within American mainstream culture (Leake \& Black, 2005; Luft, 2008). However, given the wide variations in acculturation to American mainstream values, it is not possible to determine a particular youth's orientation based on ethnic/racial status alone. Rather, each youth should be approached as an individual, with open-minded acceptance and understanding of his or her values, strengths, and needs as the basis for developing supportive mentoring relationships (Harry, Kalyanpur, \& Day, 1999). Depending on the individual, one goal might be to support development of the attitudes and skills needed to be bicultural, that is, comfortable and capable in both the home culture and the 
American mainstream culture that is predominant in postsecondary education and workplace settings (Valenzuela \& Martin, 2005).

\section{Limitations and Future Research}

The information obtained on mentoring through the interview survey tended to lack depth because time constraints precluded follow-up questions to gain more information or ensure that interviewees understood the mentoring concept. Furthermore, although all major ethnic/racial groups in the United States were represented, the numbers of participants were too small to support strong statistical comparisons between groups, and it was not possible to identify clear cultural differences with regard to mentoring. The qualitative focus groups and case studies did yield more in-depth data concerning mentoring. A limitation of the focus group data is that close to half of the participants only attended one or two out of the three sessions, so their full perspectives on mentoring may have been missed. There were only 11 case study participants, which is too few to assert generalizability of the results. On the other hand, the prominent roles that informal mentors played in the college careers of all of the case study participants confirms the potential importance of this practice.

It is also likely that the overall sample lacks representativeness. As with most research on people with disabilities, and marginalized populations in general, it proved difficult to recruit participants except through offices or agencies providing services. Youth with disabilities who do not use these services were therefore unlikely to hear of the study. In addition, there was a self-selection process for those who volunteered to participate. The relatively small monetary compensation may have been an incentive for some, but many told the researchers they were glad for the opportunity to tell their stories. In this regard, it is possible that one motivation of some participants was to contribute to research that might help others with disabilities.

Given the potential utility of mentoring, future research should pose more in-depth, focused questions about the mentor relationship. It would be particularly useful to explore how informal mentoring tends to occur in different cultures, and how formal mentoring can be structured to best meet the needs and values of youth with disabilities from different cultures.

\section{Conclusion}

Mentors can provide critical supports to CLD youth with disabilities during their transition from high school to college and careers. Through 119 survey interviews, 12 focus groups of 60 participants, and 11 case studies, the majority of the participants across six unique ethnic/racial groups described how mentors encouraged them to set their goals high and provided social, academic, and career supports. Few of the participants reported they had been in formal mentoring programs, but most reported benefiting from informal mentoring relationships with a range of people from their communities. Many of the participants attributed their success, at least in part, to the encouragement their mentors provided during high school. It is recommended that more formal mentoring programs be established to provide CLD youth with disabilities, especially those who live in remote or impoverished communities, the encouragement and assistance they need to successfully transition to college and careers.

\section{References}

Baller, W. R. (1936). A study of present social status of a group of adults, who, when they were in elementary schools, were classified as mentally deficient. Genetic Psychology Monographs, 18, 165-244.

Bhattacharjee, Y. (2007). NSF, NIH emphasize the importance of mentoring. Science, 317, 1016. doi:10.1126/science.317.5841.1016b

Blackorby, J., \& Wagner, M. (1996). Longitudinal postschool outcomes of youth with disabilities: Findings from the National Longitudinal Transition Study. Exceptional Children, 62, 399-413.

Burgstahler, S. (2007). Creating an e-mentoring community: How DO-IT does it, and how you can do it, too. Seattle: University of Washington.

http://www.washington.edu/doit/Mentor/

Burgstahler, S., \& Cronheim, D. (2001). Supporting peer-peer and mentor-protégé relationships on the Internet. Journal of Research on Technology in Education, 34, 59-74.

Campbell, T. A., \& Campbell, D. E. (2007). Outcomes of mentoring at-risk college students: Gender and ethnic matching effects. Mentoring \& Tutoring: Partnership in Learning, 15, 135-148. doi:10.1080/13611260601086287

Campbell-Whatley, G. D. (2001). Mentoring students with mild disabilities: The "nuts and bolts" of program development. Intervention in School and Clinic, 36, 211-216. doi:10.1177/105345120103600403

Campbell-Whatley, G. D., Algozzine, B., \& Obiakor, F. F. (1997). Using mentoring to improve academic programming for African American male youths with mild disabilities. School Counselor, 44, 362-367.

Chao, G. T., Walz, P. M., \& Gardner, P. D. (1992). Formal and informal mentorships: A comparison on mentoring functions and contrast with nonmentored counterparts. Personnel Psychology, 45, 619-636. doi:10.1111/j.1744-6570.1992.tb00863.x

Donovan, M. S., \& Cross, C. T. (Eds.) (2002). Minority students in special and gifted education. Washington DC: National Academy Press, National Research Council Committee on Minority Representation in Special Education.

Dynarski, M. (2001). Making do with less: Interpreting the evidence from recent federal evaluations of dropout-prevention programs. Paper presented at conference on "Dropouts: Implications and Findings”, Harvard University, Cambridge, MA.

http://www.mathematica-mpr.com/PDFs/makingdo.pdf

Flannery, K. B., Yovanoff, P., Benz, M. R., \& Kato, M. M. (2008). Improving employment outcomes of individuals with disabilities through short-term postsecondary training. Career Development for Exceptional Individuals, 31, 26-36. doi:10.1177/0885728807313779

Flexer, R. W., \& Baer, R. M. (2004). Life satisfaction and productive futures. In R. W. Flexer, T. J. Simmons, P. Luft, \& R. M. Baer (Eds.), Transition planning for secondary students with disabilities (2nd ed.). (pp. 2-19). Upper Saddle River, NJ: Pearson Education.

Gajar, A. (1998). Postsecondary education. In F. R. Rusch, \& J. G. Chadsey-Rusch (Eds.), Beyond high school: Transition from school to work (pp. 385-405). Belmont, CA: Wadsworth.

Gil-Kashiwabara, E., Hogansen, J. M., Geenan, S., Powers, K., \& Powers, L. E. (2007). Improving transition outcomes for marginalized youth. Career Development for Exceptional Individuals, 30, 80-91. doi:10.1177/08857288070300020501

Gliedman, J., \& Roth, W. (1980). The unexpected minority: Handicapped children in America. New York, NY: Harcourt Brace Jovanovich.

Greene, G., \& Nefsky, P. (1999). Transition for culturally and linguistically diverse youth with disabilities: Closing the gaps. Multiple Voices for Ethnically Diverse Exceptional Learners, 3, 15-24.

Hamilton, S. F., \& Hamilton, M. A. (1992). Mentoring programs: 
Promise and paradox. Phi Delta Kappan, 73, 546-550.

Harry, B., Kalyanpur, M., \& Day, M. (1999). Building cultural reciprocity with families. Baltimore, MD: Paul $\mathrm{H}$. Brookes.

Hebert, Y. (2001). Identity, diversity and education: A critical review of the literature. Canadian Ethnic Studies Journal, 33, 155-185.

Henderson, C. (1999). College freshmen with disabilities: A biennial statistical profile. Washington, DC: Heath Resource Center.

Herrera, C., Vang, Z., \& Gale, L. Y. (2002). Group mentoring: A study of mentoring groups in three programs. Philadelphia, PA: Public/ Private Ventures.

Hollins, S., Downer, J., Farquarson, L., Oyepeju, R., \& Kopper, L. (2002). Speaking up for myself. London: The Royal College of Psychiatrists.

Individuals with Disabilities Education Improvement Act of 2004, PL 108-446, 20 U.S.C. § 1400 et seq.

Izzo, M., Sharpe, M. N., \& Murray, A. (2002). Post-graduation follow-up survey on technology and work outcomes. Honolulu, HI: National Center for the Study of Postsecondary Educational Supports, University of Hawaii at Manoa.

www.rrtc.hawaii.edu/documents/products/phase2/pdf/059d(2)-H01.p df

James, R. K., \& Leake, D. W. (1994). Partial validation of a model of transition from school to adult environments. Education Perspectives, 28, 32-36.

Kilburg, G. M. (2007). Three mentoring team relationships and obstacles encountered: A school-based case study. Mentoring \& Tutoring: Partnership in Learning, 15, 293-308. doi:10.1080/13611260701202099

Kram, K. E. (1985). Mentoring at work: Developmental relationships in organizational life. Glenview, IL: Scott Foresman.

Lavin-Colky, D., \& Young, W. H. (2006). Mentoring in the virtual organization: Keys to building successful schools and businesses. Mentoring \& Tutoring: Partnership in Learning, 14, 433-447.

Leake, D. W., \& Black, R. S. (2005). Cultural and linguistic diversity: Implications for transition personnel. Minneapolis, MN: National Center for Secondary Education and Transition. http://www.minority.hawaii.edu/final_products/

Leake, D. W., Burgstahler, S., Rickerson, N., Applequist, K., Izzo, M., Picklesimer, T., \& Arai, M. (2006). Literature synthesis of key issues in supporting culturally and linguistically diverse students with disabilities to succeed in postsecondary education. Journal on Postsecondary Education and Disability, 18, 149-165.

Luft, P. (2008). Multicultural and collaboration competencies for working with families. In R. W. Flexer, R. M. Baer, P. Luft, \& T. J. Simons (Eds.), Transition planning for secondary students with disabilities (3rd ed.) (pp. 54-81). Upper Saddle River, NJ: Pearson Education.

Margolin, S. (2007). Non-aggressive isolated and rejected students: School social work interventions to help them. School Social Work Journal, 32, 46-66.

Mazurek-Melnyk, B. (2007). The latest evidence on the outcomes of mentoring. Worldviews on Evidence-Based Nursing, 4, 170-173. doi:10.1111/j.1741-6787.2007.00099.x

Mitchell, H. J. (1999). Group mentoring: Does it work? Mentoring \& Tutoring: Partnership in Learning, 7, 113-121. doi:10.1080/1361126990070202

Mount, B. (1997). Person-centered planning: Finding directions for change using personal futures planning. New York, NY: Graphic Futures.

National Alliance for Secondary Education and Transition. (2005). National standards and quality indicators: Transition toolkit for sys- tems improvement. Minneapolis: University of Minnesota, National Center on Secondary Education and Transition.

Newman, L., Wagner, M., Cameto, R., \& Knokey, A.-M. (2009). The post-high school outcomes of youth with disabilities up to 4 years after high school. A report of findings from the National Longitudinal Transition Study-2 (NLTS2) (NCSER 2009-3017). Menlo Park, CA: SRI International.

Nisbet, J. (Ed.) (1992). Natural supports in school, at work, and in the community for people with severe disabilities. Baltimore, MD: Paul H. Brookes.

Ragins, B. R. (2002). Understanding diversified mentoring relationships: Definitions, challenges, and strategies. In D. Clutterbuck \& B. R. Ragins (Eds.), Mentoring and diversity: An international perspective (pp. 23-53). Boston, MA: Butterworth- Heinemann.

Ragins, B. R., \& Cotton, J. L. (1999). Mentor functions and outcomes: A comparison of men and women in formal and informal mentoring relationships. Journal of Applied Psychology, 84, 529-550. doi:10.1037/0021-9010.84.4.529

Rajuan, M., Beijaard, D., \& Verloop, N. (2007). The role of the cooperating teacher: Bridging the gap between the expectations of cooperating teachers and student teachers. Mentoring \& Tutoring: Partnership in Learning, 15, 223-242.

Saito, R. N., \& Blyth, D. A. (1992). Understanding mentoring relationships. Minneapolis, MN: Search Institute.

Sipe, C. (1999). Mentoring adolescents: What have we learned? In J. B. Grossman (Ed.), Contemporary issues in mentoring (pp. 10-23). Philadelphia, PA: Public/Private Ventures. http://www.ppv.org/content/reports/issuesinmentoring_pdf.html

Sipe, C. L. \& Roder, A. E. (1999). Mentoring school-age children: A classification of programs. Philadelphia, PA: Public/Private Ventures.

Sword, C., \& Hill, K. (2003). Creating mentoring opportunities for youth with disabilities. American Rehabilitation, 27, 14-17.

Templin, M. A., Engeman, J. F., \& Doran, R. L. (1999). A locally based science mentorship program for high achieving students: Unearthing issues that influence affective outcomes. School Science and Mathematics, 99, 205-212. doi:10.1111/j.1949-8594.1999.tb17475.x

US Department of Education (2002). Twenty-fourth annual report to Congress on the implementation of the individuals with disabilities education act. Washington DC: Author.

Utsey, S. O., Howard, A., \& Williams, O. (2003). Therapeutic group mentoring with African American male adolescents. Journal of Mental Health Counseling, 25, 126-139.

Valenzuela, R., \& Martin, J. E. (2005). Self-directed IEP: Bridging values of diverse cultures and secondary education. Career Development for Exceptional Individuals, 28, 4-14. doi: $10.1177 / 08857288050280010301$

Wagner, M., Newman, L., Cameto, R., Garza, N., \& Levine, P. (2005). After high school: A first look at the postschool experiences of youth with disabilities. A report from the National Longitudinal Transition Study-2 (NLTS2). Menlo Park, CA: SRI International.

Wanberg, C. R., Kammeyer-Mueller, J., \& Marchese, M. (2006). Mentor and protégé predictors and outcomes of mentoring in a formal mentoring program. Journal of Vocational Behavior, 69, 410-423. doi:10.1016/j.jvb.2006.05.010

Westerlund, D., Granucci, E. A., Gamache, P., \& Clark, H. B. (2006). Effects of peer mentors on work-related performance of adolescents with behavioral and/or learning disabilities. Journal of Positive Behavior Interventions, 8, 244-251. doi:10.1177/10983007060080040601 